\title{
A formação da consciência social dos jovens no horizonte da Educação Histórica
}

The formation of the young people's social consciousness in the horizon of history education

\section{Maria Isabel Gomes Barca Oliveira*}

Universidade do Minho

Resumo No Projeto "Consciência Histórica-Teoria e Práticas" que, têm explorado as narrativas de jovens lusófonos acerca do mundo contemporâneo, numa primeira fase, participaram estagiários de História de três universidades portuguesas, e em fases subsequentes, jovens em final de escolaridade obrigatória em Portugal, Brasil e Moçambique. A análise indutiva das narrativas sugeriu que os jovens destes países revelam uma identidade nacional relativamente fundamentada, sem xenofobias. Quanto às narrativas globais, as dos jovens portugueses e moçambicanos aparecem muito menos substanciadas do que as nacionais, enquanto as dos jovens brasileiros narram a um mesmo nível a História do país e do mundo, interligando-as. As produções portuguesas e brasileiras mostram poucos protagonistas, emergindo apenas alguns "vilões". Por outro lado, os jovens brasileiros e moçambicanos mostram-se interventivos face ao presente.

PALAVRAS-CHAVE: Consciência histórica; Educação histórica; Narrativas históricas de jovens.

Abstract In the project "Historical Consciousness - Theory and Practices" has been exploring the narratives about the contemporary world, in the first phase of those studies the participants were a group of preservice trainees from three portuguese universities; in subsequent phases, the participants were youngsters attending the final years of compulsory schooling, from several regions in Portugal, Brazil, and Mozambique. The inductive analysis suggested that the youngsters reveal a relatively wellgrounded national identity, showing no signs of xenophobia. However, the world accounts given by Portuguese and Mozambican youngsters appear much less substantiated than the national ones, contrary to those of the Brazilians, who account for the history of their country and the world at the same level, interrelating them. In the accounts written by Portuguese and Brazilian students only a few individual characters appear, just a few 'villains' emerging. But, if the youngsters in Brazil and Mozambique show to be keen to intervene in their time.

KEYWORDS: Consciousness; History education; Youngsters' historical narratives. 


\section{Artigo}

No âmago das interrogações que filósofos, historiadores e investigadores em Educação têm manifestado atualmente em torno da formação dos jovens, encontra-se a preocupação vital de criar propostas consistentes para a construção de uma consciência social adequada, o mais possível, a estes tempos de incerteza e informação complexas. A construção de uma consciência nas novas gerações que procure o desenvolvimento pessoal e social dos seres humanos exige uma atitude de alerta incessante na busca do bem individual, mas também do bem comum, em detrimento de uma simples orientação para a satisfação de interesses egoístas, sejam individuais ou de pequenos grupos. Mas esta atitude humana para ser bem alicerçada implica, necessariamente, uma atenção especial à formação de uma consciência histórica de novo tipo. É movida por esta preocupação vital que a área de investigação em educação histórica, em vários países do mundo, tem sido fértil em estudos sobre consciência histórica dos jovens em situação de escolaridade. Entre esses estudos, destacar-se-á aqui os Projetos "Consciência Histórica - Teoria e Práticas"1, que têm procurado explorar e compreender as ideias de jovens de expressão portuguesa, em final da escolaridade obrigatória, acerca da História nacional e mundial contemporânea.

\section{Consciência histórica e paradigmas historiográficos: confrontos e consensos}

É já relativamente usual ouvir-se falar sobre "consciência histórica". Contudo, se pretendemos ultrapassar um entendimento de senso comum sobre o que é "ter consciência histórica”, concluímos que tal não é fácil de identificar. Com efeito, esse conceito tem sido frequentemente confundido com identidade de caráter exclusivista, ganhando umas vezes contornos de identidade nacional, outras de identidade local ou até de simples sentido de pertença a um grupo específico, seja social, econômico, político, religioso ou outro. Por isso, a ideia de consciência histórica tem sido atualmente objeto de discussão teórica aprofundada, com a preocupação de clarificar os seus significados e de distingui-lo de simples posturas emocionais e estáticas, relacionadas com sentidos de pertença a um qualquer grupo em que o indivíduo se insere.

Os contributos de autores como Rüsen (1993, 2001, 2010), Shemilt (2000), Lee (2002) e Seixas (2004) para a discussão epistemológica sobre as relações da História com a vida prática têm permitido identificar algumas âncoras de análise da consciência histórica de jovens e professores de História, tendo em vista um Ensino de História mais frutuoso:

a) A consciência histórica constitui uma atitude de orientação temporal sustentada refletidamente pelo conhecimento da História, e distingue-se de uma simples resposta de senso comum às exigências práticas em termos de sentimentos de identidade. A distinção entre consciência histórica e um certo sentido de identidade revela-se complexa, a avaliar pelos próprios estudos existentes sobre narrativas dos jovens acerca do passado. A destrinça e relações entre esses dois conceitos merecem uma discussão aí focalizada. 
b) "Ter consciência histórica" não implica a adoção, por todos, de um determinado paradigma historiográfico, nem tão pouco significa a defesa de uma única narrativa substantiva. As abordagens teóricas estão abertas a discussão, tal como as produções históricas concretas permanecem sujeitas a refutação. É a argumentação racional e o respeito pela evidência que ajudarão a decidir entre respostas mais ou menos válidas.

c) "Ter consciência histórica" avançada implica adquirir um certo sentido do que é a História como disciplina acadêmica, dominar determinadas competências historiográficas, construir uma narrativa histórica (não a narrativa) da condição humana (e não apenas do seu país) e refletir (e agir, intervir?) em consonância com o esquema mental que cada um vai dinamicamente formando.

Estes princípios pressupõem uma abordagem multiperspectivada da História, mas refletem também as apreensões, por parte de investigadores em cognição histórica, da influência na Educação em vários países, de tendências pós-modernistas que tendem a legitimar ao mesmo nível todas as produções sobre o passado. E se tais tendências, que chegam à negação de uma realidade extra-textual, podem ser perfilhadas, ignoradas ou combatidas pelos historiadores, de acordo com o(s) paradigma(s) que adotaram, elas merecem ser discutidas e ponderadas seriamente pelos educadores de jovens que aprendem História, e que facilmente podem ser seduzidos por frases do tipo "como posso saber a verdade se o passado não existe, ou se não estive lá?", refletindo o paradigma de observação direta, alheio à natureza da História, que é um conhecimento mediado por fontes (BARCA, 2000; GAGO, 2001).

Em ordem a um pensamento histórico (e social) mais elaborado, impõe-se que a educação histórica não ignore o debate filosófico sobre a História e a consciência histórica. Fulbrook (2002), numa abordagem de perspetivismo não relativista, discute as características de diversos paradigmas historiográficos e a multiplicidade de metanarrativas que parecem confirmar a proclamação do "fim da grande narrativa". À desconstrução extrema, Fulbrook contrapõe uma análise em busca de respostas a questões sobre evolução ou ruptura de paradigmas que carregam consigo uma tensão quanto às possibilidades e contornos do acesso epistêmico ao "passado real". Na perspectiva desta autora, apesar de as respostas a tais questões não apontarem atualmente para um consenso, existe um conjunto de critérios metodológicos de validade partilhados pela comunidade académica e que são transversais a qualquer paradigma de História:

- empenhamento no trabalho com honestidade e integridade;

- ausência de distorções ou omissões voluntárias;

- aceitação da possibilidade de revisão de interpretações particulares face a nova evidência;

- e, talvez, empenhamento na fruição da criatividade do historiador enquanto escritor - sem descurar a adesão a uma noção de fidelidade ao passado².

Dentro do respeito destes critérios, aceita-se uma variedade de paradigmas historiográficos, embora por vezes incompatíveis entre si devido a divergências a priori, por exemplo no que respeita a natureza das relações entre o indivíduo e a sociedade, 
ou entre "consciência", cultura e condições materiais, ou entre escalas de longa ou curta duração. Ao nível macro, talvez os paradigmas historiográficos não sejam necessariamente abertos a falsificabilidade, tal como Popper (1961) afirmou. Com base nesses grandes paradigmas (por exemplo, os modelos rankeano, marxista, estruturalista ou pós-estruturalistas), uma variedade de metanarrativas são possíveis e, porventura, impossíveis de serem refutadas peremptoriamente. Mas quando nos movemos dos grandes quadros narrativos para o nível de narrativas mais específicas, parcelares e concorrentes, será já possível responder à questão: "qual delas é mais válida?", dentro de critérios de falsicabilidade, isto é, de possibilidade de refutação.

\section{Pesquisa sobre consciência histórica dos jovens}

Em relação com o quadro filosófico aqui apresentado, têm emergido diversos estudos sobre a consciência histórica dos jovens, no campo da investigação em Educação Histórica. Neste âmbito, vários autores procuram explorar, em estudos qualitativos, de análise intensiva, quer os retratos do passado que os jovens constroem (ASBHY, FOSTER, HOWSON \& LEE, 2008), quer os sentidos das narrativas nucleares (master narratives) que os jovens apresentam dos seus países (WERTSCH, 2002). Este autor analisou as narrativas de adultos e jovens de 15 anos na Rússia e constatou que, apesar das narrativas dos mais velhos serem mais estruturadas e substanciadas, a metanarrativa permanecia a mesma, veiculando a ideia central de um povo que conquista a liberdade contra inimigos externos. Nos seus estudos sobre conceitos de mudança, Barton (2001) encontrou entre os jovens dos Estados Unidos uma metanarrativa de progresso linear e liberdade conquistada. Letourneau e Moisan (2004) encontraram também a permanência de uma certa metanarrativa de jovens do Quebeque, que nostalgicamente invocam os constrangimentos causados pela predominância da cultura anglo-saxónica sobre os canadianos do Quebeque, tendo como consequência o impedimento à livre expressão de um povo. Barton e McCully (2005) analisaram as narrativas de jovens da Irlanda do Norte e concluíram que, sobretudo os jovens de origem católica, viam a sua história com apreensão, como fonte de divisões e de lutas. Por sua vez, Waldron e Pike (2005), na República da Irlanda, encontraram uma narrativa de progresso e liberdade para o seu país, entre os jovens irlandeses.

Contudo, entre os estudos que exploram a construção da "consciência histórica" direcionada apenas para uma mensagem nuclear referente a um determinado povo, em alguns deles é visível uma indiscriminação conceptual entre o que significa "consciência histórica" e identidade nacional. Ora a identidade do ser humano é complexa, constituída por uma rede de pertenças em que os sentimentos e ideias ligadas a um povo se integram numa relação de consenso, tensão ou, por vezes, de conflito. A(s) identidade(s) são alimentadas pelo saber histórico, mas também resultam de interesses práticos (RÜSEN, 1993). E se no século XIX se criou uma disciplina curricular de História com a intenção de formar uma identidade nacional dos jovens, estes terão o direito e o dever de aprender, no século XXI, uma História aberta ao mundo nas suas intrincadas relações, com respeito pela dignidade do ser humano de qualquer cultura. Com esta perspectiva humanista, distinguem-se os estudos e reflexões epistemológicas em educação histórica que assentam a pesquisa - ou propostas de pesquisa - numa 
destrinça essencial entre consciência histórica e identidade nacional, propondo um enfoque na compreensão da natureza da História por parte dos alunos, sem descurar a preocupação com a construção de um quadro substantivo coerente, mas aberto, sobre a história humana (LEE, 2002, 2005; SHEMILT, 2000; BORRIES, 2000; RUSEN, 2001, 2010).É este caminho, cremos, que poderá contribuir melhor para uma análise crítica do mundo atual (como consciência histórica avançada) e, assim, permitir aos jovens sustentar de forma positiva as suas necessidades de orientação temporal.

Os trabalhos atrás referidos têm exercido influência considerável na clarificação do quadro teórico e no aprofundamento de questões de investigação no âmbito da exploração de indícios da consciência histórica dos jovens: que tipos de conceptualização do passado em relação com o presente e a perspectivação do futuro emergem em jovens escolarizados? Que tipos de conceptualizações consideramos mais poderosas, à luz da reflexão teórica e das exigências da sociedade em que vivemos?

\section{Narrativas e consciência histórica de Jovens de expressão portuguesa}

$\mathrm{O}$ interesse em investigar as ideias de jovens portugueses acerca da História Contemporânea, no final da sua escolaridade obrigatória, emergiu claramente como problema de investigação a partir da análise de dados de estudos desenvolvidos em 2003, com 18 professores estagiários de História (22 a 25 anos de idade) de três universidades portuguesas (BARCA \& MAGALHÃES, 2004; BARCA, 2006). Neste trabalho preliminar, investigaram-se as relações que esses jovens estabeleciam entre a História e a sua própria orientação no tempo, a nível pessoal e social, procurando-se explorar como concebiam a História contemporânea portuguesa, quais as dimensões que privilegiavam, qual o sentido da mudança e que usos da História no seu quotidiano lhes eram perceptíveis. Com estes objetivos, e partindo da proposta de Rüsen que considera a narrativa como uma face material da consciência histórica, entre vários instrumentos de recolha de dados desenhou-se uma proposta de tarefa escrita que consistiu na apresentação de uma narrativa acerca da história portuguesa nos últimos cem anos.

A análise das narrativas escritas pelos participantes sugeriu uma mensagem nuclear, partilhada por todos, de que o presente é o resultado de uma sucessão de rupturas políticas e de uma estrutura econômica mais estável. As dimensões sociais e culturais foram raramente destacadas, sendo por vezes até omitidas. O final da Monarquia e a instauração da República, a ditadura de Salazar, a revolução democrática de 25 de Abril de 1974 e a entrada na União Européia em 1986 surgiram como os marcos políticos mais significativos. A participação portuguesa na I Guerra Mundial, a neutralidade na II Guerra e a Guerra Colonial em África foram acontecimentos também por vezes referidos.

Sobre a mudança em história, as narrativas parecem refletir implicitamente a ideia de que os portugueses concentram as sua energias e esperanças de transforma- 
ção do país em momentos específicos de viragem para, em situações de rotina, constatarem que os problemas continuam. Todos os jovens entrevistados referiram-se positivamente às mudanças políticas de 1974 no sentido do restabelecimento de um estado democrático, mas referiram também os problemas econômicos persistentes, representados como quase imutáveis ou numa visão cíclica. Foi frequente a alusão ao atraso econômico do país, mas sem apresentação de fatores históricos que o explicassem.

Se algumas narrativas assumiram uma relação empática com êxitos e fracassos no passado, dos homens (e, por vezes, das mulheres), estes jovens estagiários raramente se colocaram na História como potenciais agentes de mudança. Eles viam a História como espectadores passivos de algo que receberam como legado dos seus antecessores.

Os resultados da análise dos dados deste estudo levou a equipa a considerar a necessidade de explorar as mesmas questões numa população mais jovem, em final de escolaridade obrigatória (14-17 anos de idade), numa primeira fase em Portugal e, em seguida, noutros países de expressão portuguesa.

Assim, entre 2004 e 2011, desenvolveu-se um estudo qualitativo, em várias fases, com a intenção de reunir dados empíricos que possibilitassem um melhor entendimento das ideias dos jovens adolescentes acerca da compreensão e usos da História no seu quotidiano. A amostra participante de jovens portugueses, estratificada por regiões (norte, centro e sul do país), era constituída pelos alunos de seis turmas de $10^{\circ}$ ano de escolaridade, com e sem a disciplina de História, em escolas cujos professores mostraram disponibilidade, para que as suas turmas participassem na pesquisa. Aos alunos participantes, em cada turma, foi proposta a realização de duas tarefas individuais, escritas, com um formato muito simples, solicitando que narrassem a História nos últimos cem anos, no País e no Mundo.

Os dados obtidos com esta tarefa dupla forneceram possibilidades de análise sob múltiplas facetas. Os ângulos analisados que aqui se apresentam têm a ver com: a) o nível da estrutura narrativa; b) as ideias substantivas veiculadas; c) as mensagens nucleares, ou esquemas conceptuais transversais às produções individuais. A Figura 1 apresenta a rede conceptual inerente à análise das narrativas.

Figura 1 - Rede conceptual da análise das narrativas dos alunos.

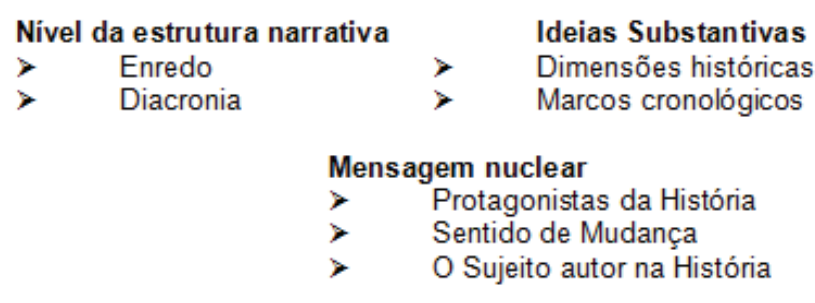

Desde a primeira recolha de dados em escolas portuguesas (2004/2005), até a última fase em 2010/2011, o resultado mais evidente e consistente foi o de se encon- 
trar um diferente grau de estruturação e de substância entre as narrativas nacionais e as globais.

As narrativas sobre a História do país oferecem uma substanciação razoável, que passa não só pela alusão sistemática a dois marcos históricos - ditadura salazarista e 25 de Abril de 1974 - como também por uma estrutura formal relativamente elaborada, constituída, na sua maioria, por "narrativas emergentes”, assim designadas por narrarem, numa forma entretecida com fatores e consequências, um dado período dentro dos cem anos - neste caso, o período correspondente aos marcos sempre mencionados (ditadura e democratização), seguido de acontecimentos da atualidade. Destas narrativas emergentes, é exemplo o relato da Joana:

Eu diria que a História de Portugal sofreu muitas mudanças sobretudo
no 25 de Abril quando o país se tornou independente, isto é, um país de-
mocrático, em 1978 [1974]. Desde então tudo foi diferente, as mulheres
foram autorizadas a votar para o governo, os Portugueses puderam ex-
pressar a sua opinião enquanto antes do 25 de Abril as pessoas não eram
autorizadas a falar sobre o governo e aqueles que se atrevessem a fazê-lo,
vinha a polícia política e prendia-os, por vezes matava-os. Não havia
liberdade de expressão, nós Portugueses tínhamos que fazer o que eles
ordenassem, mas tudo isso mudou, houve uma revolução, houve o 25 de
Abril, desde então podemos falar sobre qualquer assunto que nos apeteça.
Eagora aqui estamos nós, os Portugueses.

Além de uma maioria de "narrativas emergentes", surgem algumas produções menos elaboradas, como listagens cronológicas e comentários gerais atemporais, mas também aparece aquilo que se designou por "narrativas completas" (se narram acontecimentos e respectivas causalidades/consequências abrangendo o período de cem anos, conforme a proposta de tarefa). Considerou-se a produção da Alice como um dos exemplos de narrativa completa:

Em 1900, Portugal vivia numa Monarquia instaurando-se a República em 1910. Mais tarde, com a entrada de Portugal na I Guerra Mundial, houve perdas de muitas vidas e o país viveu tempos difíceis. Nos anos 30, Salazar entrou para o poder (era um tempo caótico) e trouxe os anos da ditadura, inspirada pelo regime fascista de Itália. Apesar da ditadura, Portugal mantere-se neutral durante a II Guerra Mundial. Durante esses anos de opressão, os portugueses viram a sua liberdade de expressão censurada e os seus homens a partir para as colónias para impor o ideal colonial de Salazar. Depois de anos de combates perdidos, em 25 de Abril de 1974 o povo revoltou-se e pôs fim aos anos penosos da ditadura, instalando um regime democrático. Outro passo importante foi a entrada para a União Europeia em 1986. Desde então, embora sendo um país livre, tem tido alguns aspectos negativos.

Por contraste, as narrativas mundiais aparecem geralmente com uma estrutura mais pobre, sobretudo como comentários não historicizados ou listagens factuais (com ou sem cronologia válida). Quando muito, e em alguns casos, surgem "narrativas emergentes”, com alusão a uma ou às duas Guerras Mundiais, à mistura com alusões a ciência e a tecnologia, seguindo-se de imediato referências a acontecimentos bélicos ou catastróficos do séc. XXI, como refere o Jorge: 
Há cerca de 100 anos...Hmm... Não sei muito bem, mas a acção de que me lembro passou-se na Alemanha, com a ditadura de Hitler. Hitler dominou vários países à volta da Alemanha, o que deu origem à $2^{a}$ Guerra Mundial. Na $2^{a}$ Guerra Mundial, os EUA e a sua aliança lutaram contra a Alemanha e o Japão. Após a libertação dos países, a Alemanha foi dominada, Hitler suicidou-se e o país foi livre do mal de Hitler. Entretanto o Japão recusava-se a render, o qual levou com que os EUA largassem uma bomba atómica no Japão.

De agora para cá, muito mudou, o mundo mudou, e a cada dia que passa custa viver cá. O aumento da poluição está a originar vários problemas que as gerações futuras vão enfrentar. Em 2001, houve um ataque terrorista às Torres Gémeas. A Grécia entrou em crise. Nestes dias, a sociedade está má. Completamente pegados às tecnologias, dependentes dos seus vicios, é cada vez mais perigoso andar na rua, as pessoas ganharam malícia, rancor... Sonho com o mundo sem guerra e sem violência. Mas digo bem, não passa de um sonho.

Os marcadores históricos privilegiados pelos jovens, nas narrativas nacionais, orientam-se sobretudo para uma dimensão sociopolítica, de média duração; nas narrativas globais, os marcadores assumem essencialmente dimensões político-militares, de ruptura, acompanhados de dimensões de caráter científico-tecnológico, temporalmente mais persistentes.

De realçar, ainda, que são raros os protagonistas individuais nestas narrativas dos jovens. Na História nacional, o povo, os militares, os políticos aparecem geralmente no coletivo. Excetuando protagonistas mediáticos do presente, as personagens individuais, quando são identificadas, retratam vilões da História - como Salazar para Portugal e Hitler para o mundo.

Estes padrões conceptuais quanto a estrutura narrativa, marcadores históricos e personagens, têm permanecido de forma consistente nas várias recolhas de dados em Portugal. Contudo, nas recolhas mais recentes, assomam algumas mudanças acerca, precisamente, dos sentidos de mudança histórica do passado até ao presente, e que merecem ser destacadas. Com efeito, até 2009 as produções dos jovens sobre o pais apresentavam uma tendência otimista de progresso, por vezes em tom mais moderado quando incluíam a menção de dificuldades econômicas na atualidade; nas produções sobre a História mundial, a mudança apresentava um sentido pessimista, marcado pela guerra, terrorismo e catástrofes ambientais e humanas, embora frequentemente também moderado pelo reconhecimento da evolução científica e tecnológica. Com os vários sinais que as produções apresentam, poderá resumir-se deste modo a metanarrativa indiciada pelos jovens portugueses até pouco tempo atrás:

Em Portugal conquistámos a democracia após um período de ditadura embora a crise econômica persista; no Mundo, há guerras e terrorismo mas há progresso científico e tecnológico.

Nesta mensagem nuclear, com características bastante homogêneas entre jovens portugueses, o sujeito, autor da narrativa, aparece como externo à História, tal como acontecera nas narrativas dos professores estagiários de História. Implicitamente, os jovens vêem-se como os herdeiros de gentes do passado, mas não como agentes do presente. 
O mesmo não acontece, contudo, nas recolhas de dados realizadas também noutros países lusófonos, nomeadamente no Brasil (Curitiba, Goiânia, São Paulo) e Moçambique (Maputo), com utilização da mesma proposta de tarefas. De sublinhar que a implementação desta pesquisa no Brasil, com a colaboração da investigadora M. Auxiliadora Schmidt, possibilitou o início de estudos comparativos transnacionais sobre narrativas e consciência histórica de jovens portugueses e brasileiros (COMPAGNONI et al., 2006; SCHMIDT, 2008; BARCA \& SCHMIDT, 2009), e agora

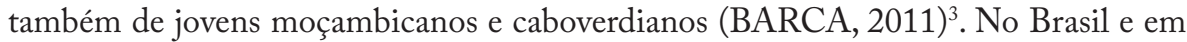
Moçambique, entre os participantes no estudo são vários os jovens que se mostram empenhados em criticar aspectos do presente, tomar posição e, até, apresentar sugestões. Por exemplo, a Rita, de 14 anos, de Curitiba, pondera que "O Brasil já mudou muito de lá para cá, apesar de ainda haver muitas injustiças em nosso país, muitos políticos corruptos. Há muita coisa que o Brasil precisa mudar". E a Iva, de 16 anos, de Maputo, capital de Moçambique, sugere que "há que melhorar as infra-estruturas, as vias de comunicação, os transportes, fazer melhoramentos na área da saúde, educação e cultura”.

A maior ou menor estrutura e substanciação das produções poderá significar algo em termos de identidade. As narrativas nacionais dos alunos moçambicanos aparecem com frequência, tal como as dos alunos portugueses, muito mais estruturadas e substanciadas do que as "narrativas" mundiais. Já nas produções dos jovens brasileiros não é visível uma diferença acentuada neste domínio: nas suas "narrativas", quer nacionais quer mundiais, predomina a forma de narrativa emergente, de caráter binário (um "antes" e um "agora”, e o país é, muitas vezes, visto em contexto mais vasto, internacional. As direções de mudança aproximam-se, contudo, das perspectivas dos jovens portugueses e moçambicanos: uma ênfase no progresso para o país, uma ideia mais pessimista para o mundo global.

As mais recentes recolhas destas produções de jovens em Portugal (2010/2011) têm mostrado que a História nacional, vista pelos olhares juvenis, parece conhecer novos ventos. Se nestes últimos dados os níveis da estrutura narrativa, os marcadores da História, os marcos cronológicos e a ausência de protagonismos individuais se mantêm, a ideia de mudança no país assume uma orientação pessimista, pelos cenários carregados que traçam sobre o presente e o futuro próximo (a ideia de mudança global mantém-se, também, pessimista). O jovem sujeito abandona a sua cadeira de espectador e aparece agora a tomar posição:

Nos últimos 100 anos, o meu país melhorou muito, mas estamos perante uma grande crise, e os países estrangeiros não nos querem ajudar, compramos submarinos para nada, o dinheiro gasto nos submarinos podia ajudar a baixar a divida externa.

O meu país, Portugal, nestes últimos 100 anos tem evoluido a nivel de tecnologia e estilo de vida, somos um país médio pois há países piores do que o meu como também há países mais evoluidos. O meu país também está em crise, já estivemos pior, é um facto, mas eu com os meus 15 anos nunca vi uma crise, ou seja, isto para mim está mau e é uma novidade pois agora tenho que me privar de muitas coisas, é uma coisa que eu odeio. Esta crise deu-se ao facto de o porvo português não tomar uma atitude, o povo português é daqueles que "ah, está mal? Deixo andar". Mas também ao facto de termos [...], o povo está a dormir e vai ter que acordar o mais rápido possivel. 
A riqueza dos resultados decorrentes da análise de dados (que está longe de ter se esgotado) levou a que as linhas gerais da metodologia do estudo se tenham mantido, perspectivando-se a sua aplicação noutros países, nomeadamente noutros espaços lusófonos e iberoamericanos.

\section{Reflexões finais}

Os resultados destes estudos constituem alguns ângulos das explorações das narrativas de jovens de expressão portuguesa sobre a História, enquanto indicadores das suas identidades em relação com a consciência histórica. Tais resultados, embora não sejam generalizáveis porque se desenvolvem em ambiente de estudos qualitativos, apresentam alguns indícios úteis para o Ensino da História, numa perspectiva de contribuir positivamente para a construção da orientação temporal dos alunos. Reportamse aqui alguns desses indícios no que diz respeito às narrativas dos jovens portugueses:

1. As narrativas livres dos jovens sugerem uma identidade nacional relativamente estruturada, com uma metanarrativa tendencialmente homogênea mas de caráter aberto, sem exclusivismos xenófobos. Há uma mudança nítida dessa mensagem nuclear em relação a que era veiculada nos tempos da ditadura (que durou desde finais dos anos 1920 até 1974). Ao contrário do que Wertsch (2004) encontrou entre adultos e jovens russos, em que a mesma narrativa nuclear tradicional, que saúda o "triunfo sobre forças estrangeiras”, permaneceu após o desmembramento da União Soviética, entre os jovens portugueses o inimigo já não é um povo externo inculcado pela escola nacionalista, mas sim esse nacionalismo, criticado como força ditatorial, interna. A identidade é assumida como um "nós" que reconquistou a liberdade e outros direitos humanos face à ditadura, o que estará radicalmente em oposição a eventuais histórias de superioridade perante outros povos. Embora não haja estudos empíricos sistemáticos sobre ideias de jovens nas décadas da ditadura, poderá dizer-se que a escola e a sociedade terão contribuído para modificar a sua narrativa nuclear acerca do país.

2. Se as narrativas nacionais sugerem uma identidade nacional saudável, a pobreza de substância das narrativas globais torna urgente a necessidade de alertar os professores para a necessidade de, na aula de História, se atender a uma discussão mais significativa dos temas contemporâneos mundiais bem como ao fortalecimento de relações conceptuais entre o passado nacional e internacional (de registar que o programa do $9^{\circ}$ ano centra-se na História do séc. XX). Uma História nacional ficará sempre amputada se não for colocada em contexto mais vasto; atender-se a estruturas e a movimentações transversais nas suas várias dimensões - culturais, sociais, políticas, científico - tecnológicas - que atravessam as sociedades em qualquer tempo, é essencial para se captarem significados genuínos de convergências, tensões e conflitos entre os seres humanos. Assim poderá tocar-se de uma forma mais consciente o sentido complexo das identidades do ser humano, muito para além da tradicional identidade nacional ou regional.

3. Os jovens quase não atendem ao indivíduo que se destaca na História pela positiva - só os vilões terão direito a protagonismo histórico? É um dado relevante para reflexão no seio da comunidade da educação histórica. O paradigma de puro 
estruturalismo historiográfico, em que o acontecimento era visto como simples espuma do tempo e o indivíduo apenas como um ator condicionado pelas estruturas, está já ultrapassado. Esta visão, que menosprezou exageradamente o papel do indivíduo na História (embora em parte por boas razões, ao recusar a preponderância das "grandes" personalidades políticas), aliada a um forte criticismo de pendor "pósmodernista", talvez tenha restringido largamente as possibilidades (pelo menos, em Portugal) de os jovens alunos prestarem atenção a homens e mulheres que, no passado, se distinguiram por pensamentos e ações ao serviço do bem comum, como agentes positivos de uma História humanizada.

4. A emergência do sujeito-autor surge recentemente na trama das narrativas dos jovens, mas com contornos de pura crítica negativa, sem revelar vontade de colocar as próprias energias criadoras ao serviço de melhores cenários para um futuro coletivo. Torna-se premente favorecer o estabelecimento de relações explicativas entre os fenômenos, nas suas causalidades e consequências, nas diversas dimensões da sociedade, e estimular a construção de novas hipóteses de futuro, que sejam não só criativas mas também objetivas.

\section{Referências}

ASBHY, R.; et al. British School Histpry Students' "Big Pictures" of the Past. Comunicação apresentada no Annual Meeting of the American Educational Research Association, Nova Iorque, 2008.

BARCA, I. O pensamento histórico dos jovens. Braga: CEEP, Universidade do Minho, 2000, $308 p$.

Consciência Histórica - Teoria e Práticas: As mensagens nucleares das narrativas dos jovens portugueses. Revista de Estudos Curriculares, Braga: Associação Portuguesa de Estudos Curriculares, n. 4 (2), 2006, p. 195-208.

Narrativas históricas de alunos em espaços lusófonos. Comunicação apresentada às XI Jornadas Internacionais de Educação Histórica, Braga, Universidade do Minho, 2011.

BARCA, I.; MAGALHÃES, O. O passado e o presente: um estudo no âmbito do Projecto Consciência Histórica - Teoria e Práticas. O Estudo da História. Lisboa: APH/ASA editora, n. 5, 2004, p. 66-75.

BARCA, I.; SCHMIDT, M. A. Consciência histórica: um diálogo entre países. In: Livro de Atas do X Congresso Luso-Afro-Brasileiro de Ciências Sociais 'Sociedades Desiguais e Paradigmas em Confronto', Braga, 2009, p. 757-765.

BARTON, K. Ideias das crianças acerca da mudança através dos tempos: resultados de investigação nos Estados Unidos e na Irlanda do Norte. In: BARCA, I. (Org.). Perspectivas em educação histórica. Braga: CIED, Universidade do Minho, 2001, p. 55-68.

BARTON, K.; McCULLY, A. Secondary Students' perspectives on School and Comunity in Northern Ireland. Comunicação apresentada no Annual Meeting of the American Educational Research Association, Montreal, 2005.

BORRIES, B. Methods and aims of teaching history in Europe: a report on Youth and History. In: STEARNS; P. ; SEIXAS, P. ; WINEBURG, S. (Eds.). Knowing, Teaching and Learning

History. New York: New York University Press, 2000, p. 246-261. 
COMPAGNONI, A.; et al. Perspectivas da Consciência Histórica em Jovens Brasileiros. In: Anais do VII Encontro Nacional de Pesquisadores em Ensino da História - ENPEH. Belo Horizonte, MG: Universidade Federal de Minas Gerais, 2006, p.1-13.

FULBROOK, M. Historical Theory. London: Routledge, 2002, 228p.

GAGO, M. Concepções dos alunos acerca da Variância da Narrativa Histórica - um estudo com alunos em anos iniciais do $2^{\circ}$ e $3^{\circ}$ ciclos do ensino básico. Dissertação de Mestrado apresentada à Universidade do Minho, Braga, 2001, 147p. (para publicação).

LEE, P. 'Walking backwards into Tomorrow': Historical Consciousness and Understanding History. Comunicação apresentada no Annual Meeting of the American Educational Research Association. SanDiego, 2002. Disponível em: http://www.cshc.ubc.ca.

Putting principles into practice: understanding history. In M. S. Donovan \& J. D. Bransford (Eds.), How students learn: history in the classroom (pp. 31-77). Washington, DC: The National Academies Press, 2005.

LETOURNEAU, J.; MOISAN, S. Young people's assimilation of a collective historical memory: A case study of Quebeckers of French-Canadian heritage. In: SEIXAS, P. (Ed.). Theorizing Historical Consciousness. Toronto: Toronto University Press, 2004, p. 109-128.

POPPER, K. The poverty of historicism. London: Routledge, and Kegan Paul, 1961, 166p.

RÜSEN, J. The development of narrative competence in historical learning: an ontogenetic hypothesis concerning moral consciousness. In: DUVENAGE, P. (Ed.). Studies in metahistory. Pretoria: Human Sciences Research Council, 1993, p. 63-84.

RÜSEN, J. Razão histórica. Teoria da História: os fundamentos da ciência histórica. Brasília: Editora UnB, 2001, 194p.

RÜSEN, J. O desenvolvimento da competência narrativa na aprendizagem histórica: uma hipótese ontogenética relativa à consciência moral. In: SCHMIDT, M. A.; BARCA, I. ; MARTINS, E. R. (Orgs.). Jörn Rüsen e o ensino de História. Curitiba-PR: Editora UFPR, 2010, p. 51-77.

SCHMIDT, M. A. Perspectivas da consciência histórica e da aprendizagem em narrativas de jovens brasileiros. Revista Tempos Históricos. Cascavel (PR): Editora Unioeste, v. 12, n. 1, ano X, 2008, p. 81-96.

SEIXAS, P. (Ed.) Theorizing Historical Consciousness. Vancouver: University of Toronto Press, 2004, 255p.

SHEMILT, D. The Caliph's Coin: the currency of narrative frameworks. In: STEARNS, SEIXAS, P.; WINEBURG, S. (Eds.). Knowing, Teaching and Learning History. New York: New York University Press, 2000, p. 83-101.

WALDRON, F.; PIKE, S. Children's construction of National Identity: what does it mean to be Irish? Comunicação apresentada no Annual Meeting of the American Educational Research Association, Montreal, 2005.

WERTSCH, J. Voices of Collective Remembering. Cambridge: CUP, 2004, 202p.

Notas

${ }^{1}$ Projetos Consciência Histórica - Teoria e Práticas I e II, (2003-2011), financiados pela Fundação para a Ciência e Tecnologia, Portugal, (http://www.fct.mctes.pt/projectos/pub/2006/Painel_Result/).

${ }^{2}$ Fulbrook, 2002, p. 50 , tradução abreviada para língua portuguesa.

${ }^{3}$ Os dados dos jovens caboverdianos, ainda não analisados de forma sistemática, foram recolhidos com a colaboração da Mestre Graça Sanches, do Ministério da Educação, de Cabo Verde. 
* Professora doutora da Universidade do Minho, Braga, Portugal.

\section{Correspondência}

Maria Isabel Gomes Barca Oliveira - Centro de Investigação em Educação (CIED) - Universidade do Minho. Campus de Gualtar. 4710-057 - Braga, Portugal.

E-mail: isabar@ie.uminho.pt

Recebido em 03 de junho de 2015

Aprovado em 18 de agosto de 2015 